\title{
Serum concentration of visfatin is decreased in patients with chronic heart failure
}

\author{
Ewa Straburzyńska-Migaj ${ }^{1}$, Łucja Pilaczyńska-Szcześniak², Alicja Nowak² ${ }^{2 \bowtie}$, Anna \\ Straburzyńska-Lupa3, Ewa Śliwicka² and Stefan Grajek \\ 11st Department of Cardiology, Poznań University of Medical Sciences, Poznań, Poland; 2Department of Hygiene, Chair of Physiology, Biochem- \\ istry and Hygiene, University School of Physical Education, Poznań, Poland; ${ }^{3}$ Department of Physiotherapy, University School of Physical Educa- \\ tion, Poznań, Poland
}

Background. There is an increasing interest in the role of adipocytokines in cardiovascular pathophysiology. Aim. The aim of the study was to compare visfatin levels, a novel adipokine, in patients with heart failure (HF) due to the left ventricular systolic dysfunction with those in ageand body mass index (BMI) - matched healthy controls in relation to the parameters of glucose metabolism and high sensitivity C-reactive protein (hsCRP) levels. Material/ Subjects and Methods. The study population consisted of 28 males with systolic HF referred for cardiopulmonary exercise testing, divided into two subgroups based on their NYHA class (HF patients NYHA $1+\|, n=17$, and HF patients $\left.\mathrm{NYHA}_{\text {III+IV, }} \mathrm{n}=11\right)$, and 23 controls. The following indices were measured in a serum samples: visfatin, hsCRP, glucose and lipid metabolism parameters, and the insulin resistance index $\mathrm{HOMA}_{\mathrm{IR}}$ (homeostasis model assessment insulin resistance) was calculated. Results. Concentrations of visfatin and high-density lipoprotein cholesterol (HDLcholesterol) in the HF subjects were significantly lower $(p \leq 0.01)$ than in controls. The Kruskal-Wallis test showed significant differences between three groups (controls and both subgroups of heart failure patients) in mean levels of visfatin, hsCRP, glucose, $\mathrm{HOMA}_{\mathrm{IR}}$ and $\mathrm{HDL}$-cholesterol. Conclusion. Serum visfatin concentrations in patients with systolic HF, particularly with more advanced NYHA classes, are significantly lower in comparison to healthy controls and are independent of age or anthropometric and metabolic parameters.

Key words: visfatin, insulin resistance, C-reactive protein, lipoproteins, heart failure

Received: 17 January, 2012; revised: 13 June, 2012; accepted: 24 August, 2012; available on-line: 27 August, 2012

\section{INTRODUCTION}

Heart failure (HF) becomes a serious problem in contemporary medicine because of an increasing number of patients developing this pathology and its relation with high morbidity and mortality. According to the "muscle hypothesis", the main symptom, i.e., exercise intolerance, results from complex peripheral abnormalities, in which low-grade systemic inflammation and metabolic abnormalities play an important role (Clark et al., 1996).

Visfatin is a novel adipocytokine predominantly secreted by visceral adipocytes and is presumed to have proinflammatory properties (Moschen et al., 2007). There is an increasing interest in the role of adipocytokines in cardiovascular pathophysiology (Dahl et al., 2007; Liu et al., 2009; Kadoglou et al., 2011). There are some reports on the relationship between levels of leptin (Wolk \& Somers, 2006) and apelin - another new adipokine (Chong et al., 2006; Ho et al., 2009) and heart failure severity. Their role in pathophysiology of heart failure is suggested. We have found only one report on visfatin in the HF (Ho et al., 2009).

Our aim was to compare the serum visfatin concentrations in patients with heart failure due to the left ventricular systolic dysfunction with those in age- and BMImatched healthy controls in relation to the parameters of glucose metabolism and C-reactive protein levels.

\section{MATERIALS AND METHODS}

The study population consisted of 28 males with systolic heart failure referred for cardiopulmonary exercise testing and 23 healthy subjects. Heart failure was diagnosed according to the European Society of Cardiology guidelines. All patients had left ventricular ejection fraction (LVEF) $<45 \%$ as measured by echocardiography. Coronary artery disease (CAD) was diagnosed in $12 \mathrm{pa}-$ tients $(43 \%)$ and non-ischemic dilated cardiomyopathy (DCM) in 16 (57\%). The patients with heart failure were divided into two subgroups based on their NYHA class: heart failure patients $\mathrm{NYHA}_{\mathrm{I}+\mathrm{II}}(\mathrm{n}=17)$ and heart failure patients $\mathrm{NYHA}_{\mathrm{III}+\mathrm{IV}}(\mathrm{n}=11)$.

At the time of examination, all subjects were stable and on optimal medical therapy. Twenty-four patients $(86 \%)$ were treated with angiotensin-converting enzyme inhibitor (ACEI) or angiotensin II receptor blocker (ARB), $26(93 \%)$ with beta-blocker, 24 ones $(86 \%)$ received furosemide, $14(50 \%)$ were on aldosterone antagonist, $8(30 \%)$ - on digoxin, $17(60 \%)$ — on aspirin and $18\left(64 \%\right.$ in NYHA $_{\text {I+II }}$ group and 65\% in NYHA group) - on statins. The exclusion criteria were as follows: acute or chronic inflammatory condition, recent myocardial infarction or revascularization ( $\leq 3$ months), exertional angina or arrhythmias, atrial fibrillation, diabetes mellitus, severe lung disease, severe renal insufficiency or other organ disorders significantly compromising subjects' physical capacity.

\section{e-mail: anowak@awf.poznan.p}

Abbreviations: BMI, body mass index; CAD, coronary artery disease; CRP, C-reactive protein; DBP, diastolic blood pressure; DCM, dilated cardiomyopathy; HF, heart failure; HDL, high-density lipoprotein; $\mathrm{HOMA}_{\mathbb{R}}$, homeostasis model assessment insulin resistance; LDL, low-density lipoprotein; LVEF, left ventricular ejection fraction; MCP-1, monocyte chemoattractant protein; peak $\mathrm{VO}_{2}$, peak oxygen consumption; SBP, resting systolic blood pressure; TG, triglyceride 
All enrolled subjects underwent maximal cardiopulmonary exercise treadmill test performed according to the modified Bruce protocol (adding stage 0: 3 min, 1.7 $\mathrm{km} / \mathrm{h}, 5 \%$ grading). The peak oxygen consumption (peak $\mathrm{VO}_{2}$ ), carbon dioxide production, and minute ventilation were measured using a breath-by-breath technique (Sensor Medics, model $\left.V_{\max } 29\right)$. The equipment was calibrated before each test. There was continuous ECG monitoring and blood pressure measurement at each stage of exercise. Peak $\mathrm{VO}_{2}$ was defined as the highest 20 -second average during the last 60 seconds of exercise.

The control group consisted of male volunteers declaring good health status. The inclusion criteria were age, body mass and BMI as similar as possible to the patients' characteristics.

All subjects gave their informed consent to participate in the study. The study was conducted in compliance with the Helsinki Declaration and was approved by the local Ethics Committee.

Blood samples were collected between 8.00 and 9.00 a.m., fasting, from the antecubital vein. The samples were centrifuged at $5000 \mathrm{rpm}$ and $4^{\circ} \mathrm{C}$. Serum was separated and stored at $-70^{\circ} \mathrm{C}$. The following serum parameters were measured: glucose, total cholesterol, high-density lipoprotein (HDL) cholesterol, triglyceride (TG) concentrations with commercially available assays (Cormay, Poland), insulin level with a radioimmunoassay (BioSource Europe S.A., Belgium), visfatin concentration with enzyme-linked immunoassays (ALPCO Diagnostics, USA, assay sensitivity $=30 \mathrm{pg} / \mathrm{ml}$, within-assay precision $4.32 \%$ and between-assay precision $7.58 \%$ ). Serum C-reactive protein (hsCRP) was determined with a high-sensitive nephelometric method (Dade Behring, Germany).

Low-density lipoprotein (LDL) cholesterol concentrations were calculated using the formula of Friedewald $e t$ al. (1972). The insulin sensitivity index $\mathrm{HOMA}_{\mathrm{IR}}$ was calculated using the formula of Matthews et al. (1985):

$\mathrm{HOMA}_{\mathrm{IR}}=$ fasting insulin $(\mu \mathrm{U} / \mathrm{ml}) \times$ fasting glucose $(\mathrm{mmol} / \mathrm{L}) / 22.5$.

The values are given as mean, standard deviation (SD), median (Me), standard error (SE) and interquartile ranges. The normal distribution of the data was verified with the Shapiro-Wilk test. Comparisons between the heart failure patients and controls for age, anthropometric measurements, and biochemical parameters were made using the Student $t$-test or Mann-Whitney test. Comparisons for maximal oxygen uptake $\left(\mathrm{VO}_{2} \max \right)$ between the heart failure subgroups (by NYHA class) and for visfatin levels between the patients with ischemic heart disease and dilated cardiomyopathy or between patients treated and not treated with statins were made using the Mann-Whitney test. Comparisons between three groups of subjects (heart failure subgroups divided according to NYHA class and the controls) for biochemical parameters were made using the Kruskal-Wallis oneway analysis of variance by ranks with post-hoc test. The Spearman's rank analysis was used to calculate correlation coefficients. A $p<0.05$ was taken to be statistically significant. Statistical analyses were performed with the Statistica 8.0 software package.

\section{RESULTS}

Basic characteristics of the examined groups of subjects are presented in Table 1.

The heart failure group and controls did not differ significantly regarding age, body weight, BMI and waist circumference. The heart failure subjects had significantly lower resting systolic blood pressure $(p \leq 0.01)$ and diastolic blood pressure $(p<0.05)$, and a higher heart rate $(\phi \leq 0.01)$ than the controls.

Results of the laboratory assessments are shown in Table 2. Concentrations of visfatin and HDL-cholesterol in the HF subjects were significantly lower $(p \leq 0.01)$ than in the controls. There were significantly higher levels of triglycerides $(p<0.05)$, glucose $(p \leq 0.01)$ and $\mathrm{HOMA}_{\mathrm{IR}}$ $(p<0.05)$ in the HF patients in comparison to the control group. In $53 \%$ and $26 \%$ of subjects from the heart failure and control groups, respectively, the values of HO$\mathrm{MA}_{\mathrm{IR}}$ represent insulin resistance (HOMA $\geq 2.5$ ).

In the HF group there were no significant differences in visfatin concentrations between the patients with ischemic heart disease $(\mathrm{n}=12)$ and dilated cardiomyopathy ( $\mathrm{n}=16)$, (Me $\pm \mathrm{SE}$ respectively: $0.74 \pm 0.81 \mathrm{ng} /$ $\mathrm{ml}$ vs $0.51 \pm 0.54 \mathrm{ng} / \mathrm{ml} ; p=0.5155)$ and between the patients treated $(n=18)$ and not treated with statins $(n=10)$,
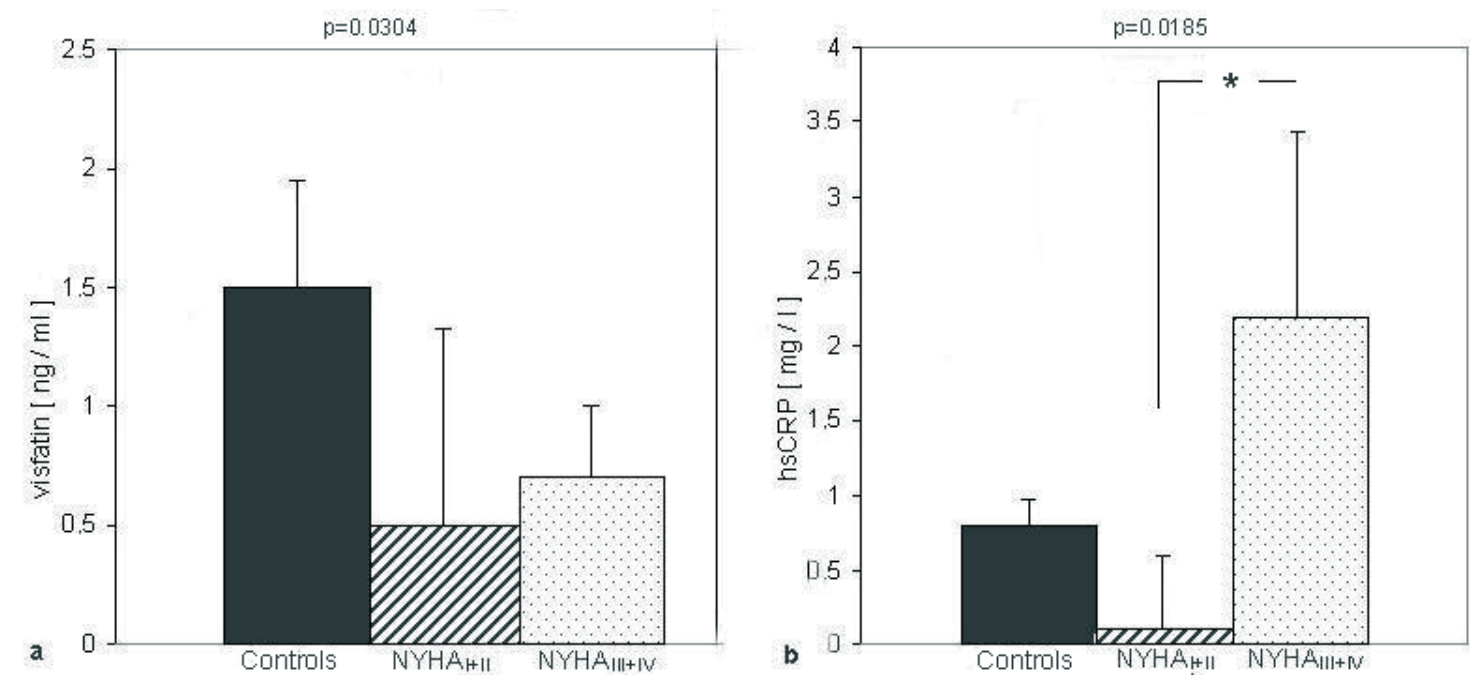

Figure 1. Serum visfatin and C-reactive protein (hsCRP) concentrations in controls and heart failure patients divided into $\mathrm{NYHA}_{1+11}$ and $\mathrm{NYHA}_{11+1 \mathrm{l}}$ class.

${ }^{*} p<0.05$, significantly different between two subgroups of heart failure patients, results are expressed as median \pm S.E; (a) serum visfatin concentrations in controls and in both subgroups of HF patients; (b) C-reactive protein (hsCRP) concentrations in controls and in both subgroups of HF patients. 

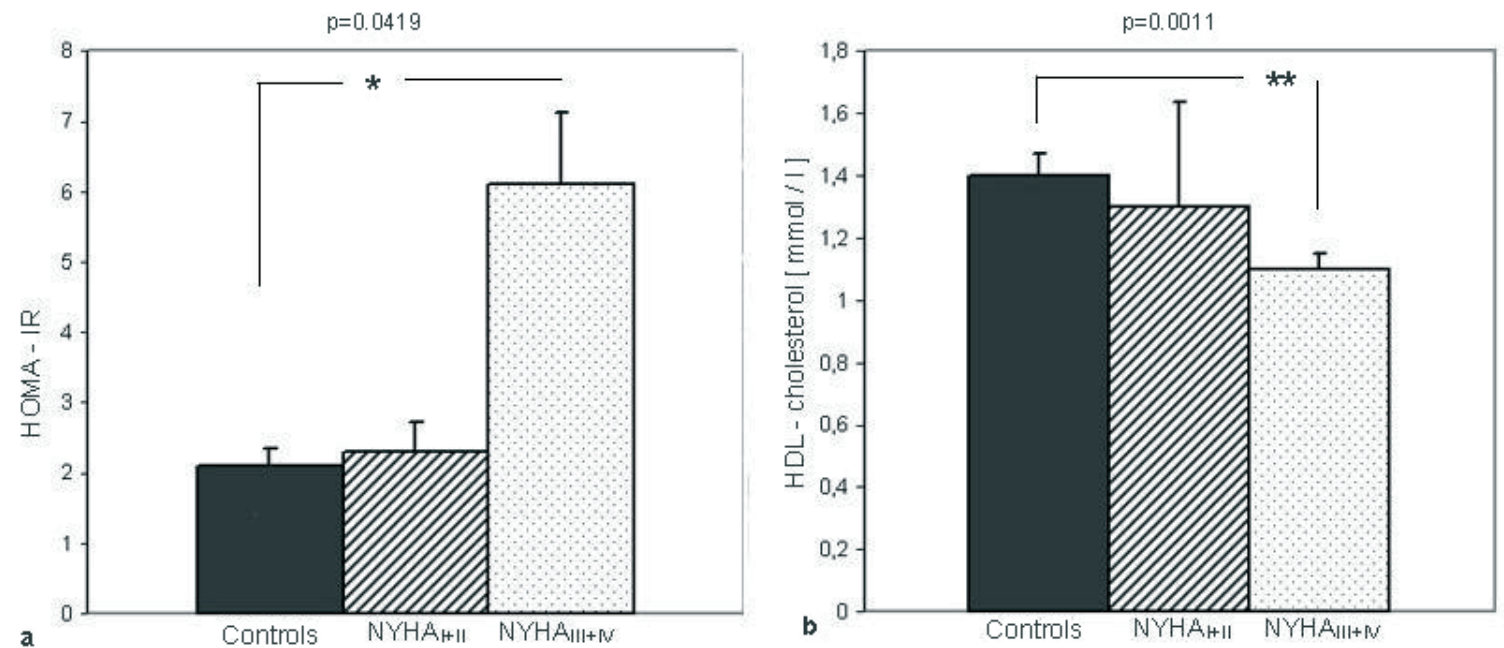

Figure 2. Homeostasis Model Assessment Insulin Resistance index (HOMA $A_{I R}$ ) values and high density lipoprotein (HDL) cholesterol concentrations in controls and heart failure patients divided into $\mathrm{NYHA}_{1+||}$ and $\mathrm{NYHA}_{\mathrm{It} \text { IV }}$ class.

${ }^{* *} p \leq 0.01,{ }^{*} p<0.05$, significantly different between subgroup of heart failure patients with NYHAllI+IV and controls, results are expressed as median \pm S.E. (a) homeostasis model assessment insulin resistance index (HOMA $A_{\mathbb{R}}$ ) in controls and in both subgroups of HF patients (b) high density lipoprotein (HDL) cholesterol concentrations in controls and in both subgroups of HF patients.

(Me \pm SE respectively: $0.60 \pm 0.36 \mathrm{ng} / \mathrm{ml}$ vs $0.82 \pm 1.28$; $p=0.2862$ ).

The Kruskal-Wallis test showed significant differences between three groups (the controls and both subgroups of HF patients divided according to NYHA I+II vs III+IV class) in levels of visfatin, hsCRP (figure 1, a and b, respectively), $\mathrm{HOMA}_{\mathrm{IR}}$, HDL-cholesterol (Fig. 2, a and $\mathrm{b}$, respectively) and glucose $(p=0.0038)$. The NYHA $\mathrm{NII+IV}$ subjects had significantly lower HDL-cholesterol concentrations $(p \leq 0.01)$ and only the tendency to decreased visfatin concentrations $(p=0.061)$. Moreover, they had higher hsCRP, HOMA ${ }_{\text {IR }}$ and glucose levels $(p<0.05)$ than the controls. In the NYHA $\mathrm{N}_{\mathrm{I}+\mathrm{II}}$ subjects, the levels of all these biochemical parameters did not differ from the controls. There was a significant difference between the two heart failure subgroups with respect to hsCRP concentrations $(p=0.0255)$. No significant differences were found between three investigated groups with respect to age, body mass, BMI and waist circumference.

The $\mathrm{NYHA}_{\mathrm{I}+\mathrm{II}}$ subjects had significantly higher mean peakVO $V_{2}(21.7 \pm 3.66 \mathrm{ml} / \mathrm{kg} / \mathrm{min})$ than the $\mathrm{NYHA}_{\mathrm{III}+\mathrm{IV}}$ ones $(14.4 \pm 4.79 \mathrm{ml} / \mathrm{kg} / \mathrm{min} ; p=0.0018)$.

In all heart failure patients, HDL-cholesterol levels correlated positively with visfatin $(\mathrm{r}=0.39, p=0.0444)$ and negatively with hsCRP concentrations ( $\mathrm{r}=-0.52$, $p=0.0053$ ), and the NYHA class correlated with hsCRP concentrations $(\mathrm{r}=0.53 ; p=0.0030)$. A trend was found

Table 1. Baseline characteristics of heart failure subjects and control group

\begin{tabular}{lccc}
\hline Characteristic & Heart failure group & \multicolumn{2}{c}{ Control group } \\
\hline Age (years) & $51.0 \pm 7.88$ & $53.0 \pm 11.47$ & 0.3203 \\
Body weight $(\mathrm{kg})$ & $82.6 \pm 11.94$ & $86.3 \pm 12.61$ & 0.3487 \\
Height $(\mathrm{cm})$ & $174.0 \pm 4.98$ & $178.6 \pm 6.28$ & $0.0100^{*}$ \\
BMI $\left(\mathrm{kg} / \mathrm{m}^{2}\right)$ & $27.3 \pm 3.84$ & $26.9 \pm 3.90$ & 0.7404 \\
Waist circumference $(\mathrm{cm})$ & $98.9 \pm 9.53$ & $95.8 \pm 9.99$ & 0.2256 \\
HR (beats/min) & $86.8 \pm 16.14$ & $74.2 \pm 10.08$ & $0.0035^{* *}$ \\
SBP $(\mathrm{mm} \mathrm{Hg})$ & $118.2 \pm 19.49$ & $133.9 \pm 18.26$ & $0.0013^{* *}$ \\
DBP $(\mathrm{mm} \mathrm{Hg})$ & $79.3 \pm 10.2$ & $87.0 \pm 11.45$ & $0.0206^{*}$ \\
\hline
\end{tabular}

${ }^{* *} p \leq 0.01 ;{ }^{*} p<0.05$. Results are expressed as mean \pm S.D. BMI, body mass index; HR, heart rate; SBP, systolic blood pressure; DBP, diastolic blood pressure. between hsCRP and peak $\mathrm{VO}_{2}(\mathrm{r}=-0.32 ; p=0.0990)$. In the control group, a relationship between visfatin concentrations and BMI was revealed $(r=0.43$, $p=0.0422$ ). Positive correlations were also found between BMI and insulin levels ( $\mathrm{r}=0.53, p=0.0088), \mathrm{BMI}$ and $\mathrm{HOMA}_{\mathrm{IR}}(\mathrm{r}=0.48, p=0.0204)$, waist circumference and insulin levels ( $\mathrm{r}=0.71, p=0.0002)$, waist circumference and $\mathrm{HOMA}_{\mathrm{IR}}(\mathrm{r}=0.64, p=0.0014)$.

\section{DISCUSSION}

The presented data show that serum visfatin concentrations are significantly lower in male subjects with heart failure due to systolic dysfunction in comparison to healthy controls. Furthermore, visfatin concentrations are lower in patients with more severe $\mathrm{HF}\left(\mathrm{NYHA}_{\mathrm{III}+\mathrm{IV}}\right)$ in comparison to mild $\mathrm{HF}\left(\mathrm{NYHA}_{\mathrm{I}+\mathrm{II}}\right)$. Concentrations of visfatin were independent of age, BMI, levels of glucose, insulin, cholesterol, and triglicerydes, HOMA ${ }_{I R}$, heart rate, and peak $\mathrm{VO}_{2}$.

An adipocytokine exerting insulin-mimicking effects, visfatin, attracts particular interest of investigators dealing with diabetes and obesity (Fukuhara et al., 2005). Despite many studies published recently, visfatin's role is unclear and results of the studies are inconsistent. It is shown that serum visfatin concentrations are increased in patients with type 2 diabetes independently of obesity (measured as BMI or waist circumference), and insulin resistance (Alghasham \& Bakarat, 2008; Esteghamati et al., 2011). But it is no more so clear in gestational diabetes, where some investigators have found increased levels of visfatin while others decreased in comparison to controls with normal glucose metabolism (Chan et al., 2006; Lewandowski et al., 2007). It has also been shown that visfatin concentrations are increased in obesity in some studies (Zahorska-Markiewicz et al., 2007), while others could not demonstrate any difference in visfatin levels between obese and non-obese groups 
Table 2. Biochemical parameters of heart failure subjects and control group

\begin{tabular}{|c|c|c|c|}
\hline Parameter & Heart failure group & Control group & $p$-value \\
\hline Visfatin (ng/ml) & $0.6(0.4-1.1)$ & $1.5(1.0-2.5)$ & $0.0095^{* *}$ \\
\hline Insulin $(\mu \mathrm{IU} / \mathrm{ml})$ & $11.2(8.0-22.5)$ & $9.5(7.0-13.9)$ & 0.1851 \\
\hline Glucose $(\mathrm{mmol} / \mathrm{l})$ & $5.7(5.3-6.2)$ & $4.8(4.1-5.6)$ & $0.0009^{* *}$ \\
\hline $\mathrm{HOMA}_{\mathrm{IR}}$ & $2.9(2.0-5.6)$ & $2.1(1.5-2.9)$ & $0.0231^{*}$ \\
\hline Total cholesterol $(\mathrm{mmol} / \mathrm{l})$ & $5.0(4.3-6.0)$ & $4.8(4.0-5.6)$ & 0.3114 \\
\hline HDL-cholesterol (mmol/l) & $1.1(0.9-1.3)$ & $1.4(1.2-1.9)$ & $0.0032^{* *}$ \\
\hline LDL-cholesterol (mmol/l) & $3.2(2.4-3.9)$ & $2.4(2.1-3.3)$ & 0.1578 \\
\hline $\mathrm{TG}(\mathrm{mmol} / \mathrm{l})$ & $1.8(0.9-2.2)$ & $0.9(0.6-1.2)$ & $0.0102^{*}$ \\
\hline $\mathrm{hsCRP}(\mathrm{mg} / \mathrm{l})$ & $1.1(0.0-2.8)$ & $0.8(0.6-1.5)$ & 0.8424 \\
\hline
\end{tabular}

${ }^{* *} p \leq 0.01 ;{ }^{*} p<0.05$. Results are expressed as median (interquartile range). $\mathrm{HOMA}_{\mathbb{R}}$, Homeostasis Model Assessment Insulin Resistance; HDL-cholesterol, high density lipoprotein cholesterol; LDL-cholesterol, low density lipoprotein cholesterol; TG, triglycerides; hsCRP, C-reactive protein.

and subjects with or without visceral fat accumulation (Ersoy et al., 2010). A study conducted in women with rheumatoid arthritis showed lower plasma visfatin concentrations in patients with abdominal obesity in comparison to those without abdominal obesity (StraburzyńskaLupa et al., 2010). The results regarding relations between anthropometric parameters and visfatin levels are also inconsistent. Some investigators found correlations between visfatin and BMI, others show no correlations (Zahorska-Markiewicz et al., 2007; Alghasham \& Bakarat, 2008; Jin et al., 2008; Caixàs et al., 2009) or even negative correlations (Chen et al., 2006). In our study there were no differences in the BMI or waist circumference between the patients and controls. We demonstrated that there was no significant correlations between visfatin levels and BMI in the HF group, while there was significant positive correlation in the control group.

Similarly controversial are results regarding relationships between visfatin and both, glucose and insulin resistance. In obesity and type 2 diabetes there is a well established association between visceral adipose tissue, lipid metabolism and insulin resistance, which in turn are associated with increased cardiovascular risk (Wajchenberg, 2000). Correlations of visfatin and insulin resistance were shown in some studies (Chen et al., 2006; Lewandowski et al., 2007) and no correlations were found in others (Pagano et al., 2006; Alghasham \& Bakarat, 2008; de Luis et al., 2008). Heart failure is regarded as an insulin resistance state in which glucose metabolism abnormalities are related to the disease severity and prognosis (Doehner et al., 2005; Straburzyńska-Migaj et al., 2007). We have demonstrated significantly higher glucose and insulin levels, and $\mathrm{HOMA}_{\mathrm{IR}}$ in our patients compared to the healthy controls, which were further higher in

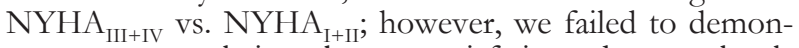
strate any correlations between visfatin and serum levels of glucose, insulin or $\mathrm{HOMA}_{\mathrm{IR}}$.

Some investigations imply that visfatin may play a role in lipid metabolism (Jin et al., 2008; Esteghamati et al., 2011), while others (Zahorska-Markiewicz et al., 2007; de Luis et al., 2008; Ersoy et al., 2010) have shown no correlations between visfatin and lipid parameters in various study populations. We have demonstrated significant correlation between visfatin and HDL-cholesterol in heart failure male patients, which confirms the results of a few other studies (Smith et al., 2006; Jin et al., 2008). No correlations were found between visfatin and lipids in the healthy controls. Wang et al. (2007), in studies on Caucasian subjects, have proposed that the association of visfatin with HDL-cholesterol may be the effect of en- zymatic function of visfatin in NAD metabolism. Recent studies have documented that statin therapy may suppress visfatin serum levels (Kadoglou et al., 2011). However, in our study the comparative analysis of visfatin levels between heart failure individuals treated and not treated with statins did not show any significant difference, but the small sample size and the large variation in visfatin concentrations could blunt the results.

Recently, a role of visfatin in inflammatory processes such as atherosclerosis or subclinical inflammation with concomitant type 2 diabetes is suggested (Alghasham \& Bakarat, 2008; Liu et al., 2009). Liu et al. (2009) have documented that plasma visfatin concentrations are significantly higher in patients with chronic coronary artery disease and acute coronary syndromes compared with control groups. In their study serum visfatin concentrations correlated with inflammatory factors (monocyte chemoattractant protein - MCP-1 and interleukin-6), but not with hsCRP or fasting glucose levels, age, waist circumference, BMI, $\mathrm{HOMA}_{\mathrm{IR}}$, or levels of cholesterol and triglycerides. Heart failure is also considered a low grade inflammatory process in which inflammatory parameters are related to disease severity and prognosis (Rauchhaus et al., 2000; Straburzyńska-Migaj et al., 2004). In the presented study we have shown that hsCRP levels are significantly higher in $\mathrm{NYHA}_{\mathrm{III}+\mathrm{IV}} \mathrm{pa}-$ tients compared to $\mathrm{NYHA}_{\mathrm{I}+\mathrm{II}}$ ones, but we documented no correlations between hsCRP and visfatin. Furthermore, we found no significant differences in visfatin levels between the patients with ischemic and non-ischemic heart failure. However, the limitation of our study is the small number of participants and the results must be approached with caution.

We have found one paper evaluating the role of visfatin and four other adipocytokines as potential prognostic factors in patients with severe heart failure and high levels of B-type natriuretic peptide (Ho et al., 2009). Visfatin was found to have no clinical importance in those patients.

Visfatin has been reported to exert several different effects with respect to cardiovascular disease (Hausenloy, 2009). On the one hand, these include endothelial dysfunction, angiogenesis, atherosclerotic plaque instability, and on the other - cardioprotection. Interesting and potentially important is a finding that visfatin may directly protect myocardium against the effects of acute ischemia-reperfusion injury at the cardiomyocyte level (Hausenloy, 2009). We are clearly at the beginning of a difficult way to explaining the role of visfatin in cardiovascular disease, including heart failure.

Concluding, we can state that serum visfatin concentration in patients with heart failure due to systolic dysfunction is significantly lower in comparison to healthy subjects. Furthermore, patients with higher NYHA classes have even lower visfatin level. Concentration of visfatin in patients with HF is independent of age, anthropometric and metabolic parameters.

\section{REFERENCES}

Alghasham AA, Bakarat YA (2008) Serum visfatin and its relation to insulin resistance and inflammation in type 2 diabetic patients with and without macroangiopathy. Saudi Med J 29: 185-192. 
Caixàs A, Tirado R, Vendrell J, Gallart L, Megía A, Simón I, Llauradó G, González-Clemente JM, Giménez-Palop O (2009) Plasma visfatin concentrations increase in both hyper and hypothyroid subjects after normalization of thyroid function and are not related to insulin resistance, anthropometric or inflammatory parameters. Clin Endocrinol (Oxf) 71: 733-738.

Chan TF, Chen YL, Lee CH, Chou FH, Wu LC, Jong SB, Tsai EM (2006) Decreased plasma visfatin concentration in women with gestational diabetes mellitus. I Soc Gynecol Investig 13: 364-367.

Chen MP, Chung FM, Chang DM, Tsai JC, Huang HF, Shin SJ, Lee YJ (2006) Elevated plasma level of visfatin/pre-B cell colony-enhancing factor in patients with type 2 diabetes mellitus. J Clin Endocrinol Metab 91: 295-299.

Chong KS, Gardner RS, Morton JJ, Ashley EA, McDonagh TA (2006) Plasma concentrations of the novel peptide apelin are decreased in patients with chronic heart failure. Eur J Heart Failure 8: 355-360.

Clark AL, Poole-Wilson PA, Coats AJS (1996) Exercise limitation in chronic heart failure: central role of the periphery. J Am Coll Cardio 28: 1092-1102.

Dahl TB, Yndestad A, Skjelland M, Øie E, Dahl A, Michelsen A, Damås JK, Tunheim SH, Ueland T, Smith C, Bendz B, Tonstad S, Gullestad L, Frøland SS, Krohg-Sørensen K, Russell D, Aukrust P, Halvorsen B (2007) Increased expression of visfatin in macrophages of human unstable carotid and coronary atherosclerosis. Possible role in inflammation and plaque destabilization. Circulation 115: 972-980.

de Luis DA, Sagrado MG, Conde R, Aller R, Izaola O (2009) Relation of visfatin to cardiovascular risk factors and adipocytokines in patients with impaired glucose tolerance. Nutrition doi:10.1016/j. nut.2008.11.005

Doehner W, Rauchhaus M, Ponikowski P, Godsland IF, von Haehling S, Okonko DO, Leyva F, Proudler AJ, Coats AJ, Anker SD (2005) Impaired insulin sensitivity as an independent risk factor for mortality in patients with stable chronic heart failure. $J \mathrm{Am}$ Coll Cardiol 46: 1019-1026.

Ersoy C, Sadikoglu G, Orhan H, Guclu M, Sarandol E, Akgun MD, Ozcakir A, Imamoglu S (2010) Body fat distribution has no effect on serum visfatin levels in healthy female subjects. Cytokine 49: 275-278.

Esteghamati A, Alamdari A, Zandieh A, Elahi S, Khalilzadeh O, Nakhjavani M, Meysamie A (2011) Serum visfatin is associated with type 2 diabetes mellitus independent of insulin resistance and obesity. Diabetes Res Clin Pract 91: 154-158.

Friedewald WT, Levy RI, Fredrickson DS (1972) Estimation of the concentration of low-density lipoprotein cholesterol in plasma, without use of the preparative ultracentrifuge. Clin Chem 18: 499-502.

Fukuhara A, Matsuda M, Nishizawa M, Segawa K, Tanaka M, Kishimoto K, Matsuki Y, Murakami M, Ichisaka T, Murakami H, Watanabe E, Takagi T, Akiyoshi M, Ohtsubo T, Kihara S, Yamashita S, Makishima M, Funahashi T, Yamanaka S, Hiramatsu R, Matsuzawa Y, Shimomura I (2005) Visfatin: A protein secreted by visceral fat that mimics the effects of insulin. Science 307: 426-430.

Hausenloy DJ (2009) Drug discovery possibilities from visfatin cardioprotection? Curr Opin Pharmacol 9: 202-207.

Ho YL, Lin YH, Lee CM, Hsu RB, Ting HT, Chou NK, Chao CL, Wang SS, Hsu HC, Chen MF (2009) Prognostic significance of adipocytokines and extracellular matrix activity in heart failure patients with high B-type natriuretic peptide. Clin Biochem 42: 1407-1412.

Jin H, Jiang B, Tang J, Lu W, Wang W, Zhou L, Shang W, Li F, Ma Q, Yang Y, Chen M (2008) Serum visfatin concentrations in obese adolescents and its correlation with age and high-density lipoprotein cholesterol. Diabetes Res Clin Pract 79: 412-418.

Kadoglou NP, Gkontopoulos A, Kapelouzou A, Fotiadis G, Theofilogiannakos EK, Kottas G, Lampropoulos S (2011) Serum levels of vaspin and visfatin in patients with coronary artery disease - Kozani study. Clin Chim Acta 412: 48-52.

Lewandowski KC, Stojanovic N, Press M, Tuck SM, Szosland K, Bienkiewicz M, Vatish M, Lewinski A, Prelevic GM, Randeva HS (2007) Elevated serum levels of visfatin in gestational diabetes: a comparative study across various degrees of glucose tolerance. Diabetologia 50: 1033-1037.

Liu SW, Qiao SB, Yuan JS, Liu DQ (2009) Association of plasma visfatin levels with inflammation, atherosclerosis and acute coronary syndromes (ACS) in humans. Clin Endocrinol 71: 202-207.

Matthews DR, Hosker JP, Rudenski AS, Naylor BA, Treacher DF, Turner RC (1985) Homeostasis model assessment: insulin resistance and beta-cell function from fasting plasma glucose and insulin concentration in man. Diabetes 28: 412-419.

Moschen AR, Kaser A, Enrich B, Mosheimer B, Theurl M, Niederegger H, Tilg H (2007) Visfatin, an adipocytokine with proinflammatory and immunomodulating properties. I Immunol 178: 1748-1758.

Pagano C, Pilon C, Olivieri M, Mason P, Fabris R, Serra R, Milan G, Rossato M, Federspil G, Vettor R (2006) Reduced plasma visfatin/ pre-B cell colony-enhancing factor in obesity is not related to insulin resistance in humans. I Clin Endocrinol Metab 91: 3165-3170.

Rauchhaus M, Doehner W, Francis DP, et al. Davos C, Kemp M, Liebenthal C, Niebauer J, Hooper J, Volk HD, Coats AJ, Anker SD (2000) Plasma cytokine parameters and mortality in patients with chronic heart failure. Circulation 102: 3060-3067.

Smith J, Al-Amri M, Sniderman A, Cianflone K (2006) Visfatin concentration in Asian Indians is correlated with high density lipoprotein cholesterol and apolipoprotein A1. Clin Endocrinol 65: 667-672.

Straburzyńska-Lupa A, Nowak A, Pilaczyńska-Szcześniak L, Straburzyńska-Migaj E, Romanowski W, Karolkiewicz J, Sliwicka $\mathrm{E}$ (2010) Visfatin, resistin, hsCRP and insulin resistance in relation to abdominal obesity in women with rheumatoid arthritis. Clin Exp Rheumatol 28: 19-24.

Straburzyńska-Migaj E, Leśniewska K, Ochotny R, Straburyńska-Lupa A, Baszko A, Wiktorowicz K, Cieśliński A (2004) Cardiopulmonary exercise testing and cytokines in chronic heart failure. Comparison of patients with ischaemic and with dilated cardiomyopathy. Pol Arch Med Wewn 111: 693-701.

Straburzyńska-Migaj E, Ochotny R, Cieśliński A (2007) Impaired glucose tolerance worsens exercise capacity and ventilatory response to exercise in patients with chronic heart failure. Kardiol Pol 4: 354-360.

Wajchenberg BL (2000) Subcutaneous and visceral adipose tissue their relation to the metabolic syndrome. Endoor Rev 21: 697-738.

Wang P, van Greevenbroek MM, Bouwman FG, Brouwers MC, van der Kallen CJ, Smit E, Keijer J, Mariman EC (2007) The circulating $\mathrm{PBEF} / \mathrm{NAMPT} /$ visfatin level is associated with a beneficial blood lipid profile. Pflugers Arch 454: 971-976.

Wolk R, Somers VK (2006) Leptin and vascular function: friend or foe? Eur Heart J 27: 2263-2265.

Zahorska-Markiewicz B, Olszanecka-Glinianowicz M, Janowska J, Kocełak P, Semik-Grabarczyk E, Holecki M, Dabrowski P, Skorupa A (2007) Serum concentration of visfatin in obese women. Metabolism 56: 1131-1134. 
